\title{
The Government and Migrant Workers in Transfer of Industry
}

\author{
Hui Zhang ${ }^{1}$ \\ ${ }^{1}$ School of Economics, Northwest University for Nationalities, Lanzhou, China \\ Correspondence: Hui Zhang, School of Economics, Northwest University for Nationalities, Lanzhou 730124, China. \\ E-mail:24060565@qq.com
}

Received: March 14, 2014

doi:10.5430/ijba.v5n3p142
Accepted: April 3, 2014

Online Published: May 6, 2014

URL: http://dx.doi.org/10.5430/ijba.v5n3p142

This work was supported by the Fundamental Research Funds for the Central Universities of Northwest University for Nationalities (Grant No: ZYZ2011017).

\begin{abstract}
The industry transfer from east region to west region of China has become an inevitable trend of economic development, it need massive agricultural population change to non-agricultural population in China. Based on the redefinition of the citizenization of migrant workers, this article points out that "absence of government" is the reason which leads to a series of relative problems. In order to solve these problems, it needs the government to take measures from the "thought" and "action". Government in the thought must be clear the rule of macroeconomic regulation and control standards, which is that the social management is more important than the economic intervention. Government must recognize that farmers and citizen have equal status with the corresponding rights, must clear the responsibilities and duties at all levels, and strengthen the central government's capacity of coordination. In order to ensure the rights and interests of migrant workers can be the truth, the government in action must take steps from the political rights, economic rights and social security. These initiatives will play a positive function in accelerating the process of the citizenization of migrant workers, and it will help the industry transfer to west areas from central areas of China.
\end{abstract}

Keywords: the citizenization of migrant workers, absence of government, transfer of industry

\section{Introduction}

To speed up the urbanization process has become a prominent feature of the inevitable trend of China's social development, although scholars are controversial on the actual level of urbanization, some of them believe that the actual level of urbanization is lower than the nominal level, but the population from rural to urban migration has exerted a great influence on economy, and it triggered a series of related problems which have become the focus and difficult problems in current economic research. The big income gap in urban and rural areas causes the migrant workers come into the city. Chart 1 shows the figure about the urban and rural' per capita income. We can find the huge gap in per capita income between the urban and rural, so the migrant workers who leave the homeland and come to the city are rational economic action.

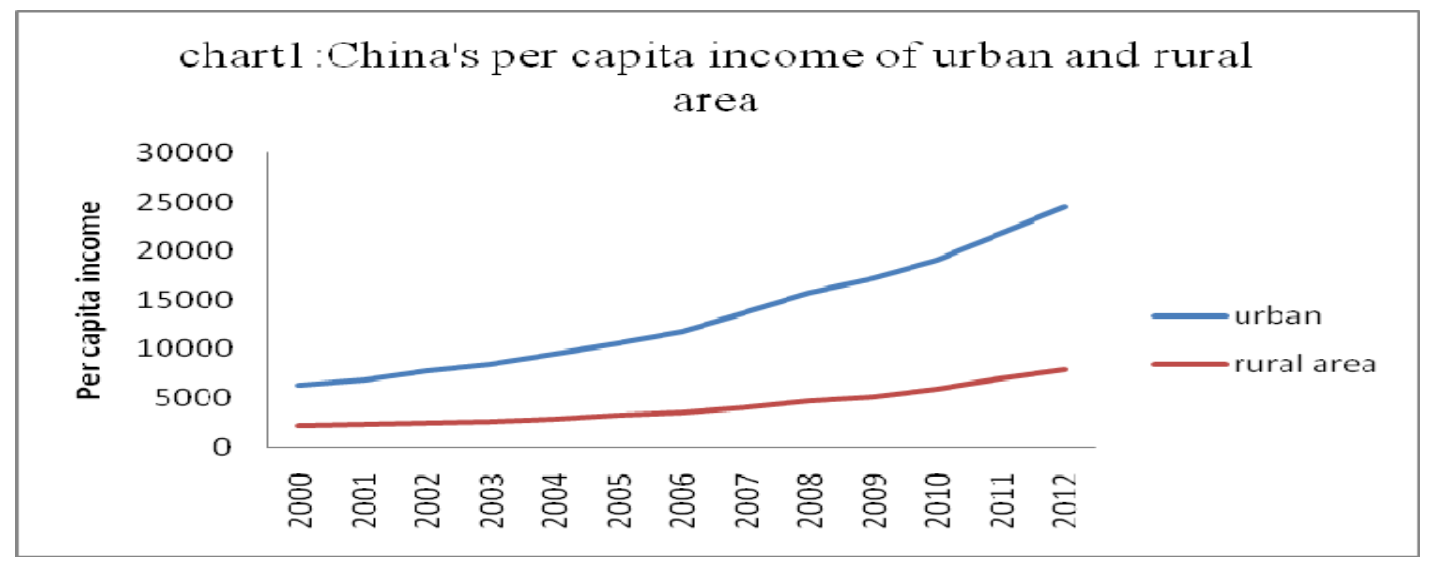


The discussion about the citizenization of migrant workers due to city and rural, citizen and farmers, the first industry and the second or the third industry, the government and the civics and other aspects of the interest relations, which is particularly prominent and concern. This paper focuses on the analysis of the absence of government in the urbanization process and tries to give responses.

\section{The New Definition of the Citizenization of Migrant Workers}

About the definition of the citizenization of migrant workers, there are a lot of expression in academia, which is representative of the views is the concept of research group of the State Council Development Research Center, the connotation of the citizenization of migrant workers is defined as: migrant workers into the city to the overall public service system is the core, to promote the peasant worker enters into enterprises, their children go to school, their family integrate into the community, or migrant workers in the city are "have the job, have the school, have a living room, have social security" (Note 1). This view of definite the citizenization of migrant workers on the town or city is the current mainstream of academic.

Based on the comprehensive reference of scholars' view: in this paper, the citizenization of migrant workers refers to all migrant workers enter into non-agricultural industries, whether they are in the city, urban or rural, can gradually enjoy equal political rights, economic rights and social security same as city residents. The citizenization of migrant workers' concept is essentially wherever they can enjoy the same treatment with the citizen; the representation is to eliminate the gap between urban and rural areas.

\section{The Problems Are Caused by the Absence of Government during the Citizenization of Migrant Workers}

Play the role of macro-control on the economy and social life is one of the basic functions of the government. But since the China's Reform and Opening-up, our government pays more attentions to economic regulation and control, such as increases economic development and improves people's income or living level, but not on the social welfare and security. The difference between urban and rural areas or social attention is relaxed. So, some scholars say: "China government only has economic policy in the first twenty years of China's Reform and Opening-up, but no social policy" (Note 2). In order to ensure the speed and benefit, the government often direct intervenes in the process of economic activities, but the government ignores the role of the market, this is the performance of offside of government. While in the process of social construction, the government tends to the city and the citizen, naturally or half unconsciously ignores the urban areas and farmers' interests, this is the performance of absence of government. So much problems expose currently in the citizenization of migrant workers are a true portrayal of the absence of government. The specific problems caused by the absence of government are:

\subsection{The Questions of Political Rights Are Caused by the Absence of Government}

The questions of political rights in the citizenization of migrant workers mainly include two aspects: one of question is how to participate the political; the other is how to guarantee the political rights. On the political participation, according to China's current law, electing a deputy to a people's congress is the main way to safeguard the people's interests, and the residence as a precondition is the condition of participate in the election of deputies. But the majority of migrant workers are generally working in the non-domicile, so they lack the basic political participation's rights in the system level where they are working at. In this case, the government has not made the explicit stipulation, so it is the absence of government. In the aspect of guaranty the political rights, the trade union, the all-china youth federation, the women's federation in the state-owned enterprises of China are only play a very limited role. In the non-state owned enterprises, one side is the above organization are not perfect, on the other hand, these institutions also fundamentally do not change ideas and concepts, they can't real integrate to the migrant workers and play the corresponding role. In this case, the government does not make the clear requirements and correct specifications, so the government's function is "absence".

Because of the above reasons, migrant workers in the process of employment once encounter infringement about their rights, they have no complaints and only keep silence and endure. Otherwise, they use some extreme ways to express their dissatisfaction. This kind of action further intensifies the social contradiction and class contradiction. How to guarantee the political rights of migrant workers has become a fundamental issue for the citizenization of migrant workers.

\subsection{The Questions of Economic Rights Are Caused by the Absence of Government}

The main two aspects of questions about economic rights for the migrant workers include: one is the problem of arrears of wages directly; two is land rights involves into the rural contracted land and homestead land. For the first problem, all levels of government take effective measures to protect the migrant workers' rights, these actions make the phenomenon of arrears of wages have been effectively curbed. That means the government has a concrete 
reflection in place. For the second problem, when it comes to the issue of land rights, the government has "absence". Now, some areas are trying to put the concept of "land for registration" in the process of citizenization, they requires farmers to give up the land rights and interests which including the rural contracted land and homestead land to exchange the urban registration. We put the political and legal's rationality of this action aside, just discuss the following economic problems: First, according to the current law, farmers have the rights to use the contracted land. When the government imposes the land not to the contract expiration, how to compensate the farmers' reasonable expected future earnings and investment? Second, according to the China's current "the guarantee law", farmer owns the all property building in homestead land, but the homestead land belongs to the village collective, these properties can not participate in the mortgage and transaction. For the farmer's homestead and house property, how to assess the land's value and make the land participates in the marketing transactions? These are most sensitive questions involving in land demolition in recent years. The government is "absence" when we ask how to solves these problems.

It is precisely because of these economic problems, when migrant workers who are most directly affected by the economic fluctuations return to the countryside, the finally safeguard for them are the land. But now, some people hope the migrant workers give up the actual income from land and in exchange for enjoying the unknown citizen treatment. So, for the citizenization of migrant workers, one of the key problem is how to ensure the economic rights and interests of migrant workers in this process.

\subsection{The Questions of Social Security and Welfare Are Caused by the Absence of Government}

The social security is hard to describe in China because there is not enough data, so we use the per capita transfer income to show the difference of social security between urban and rural.

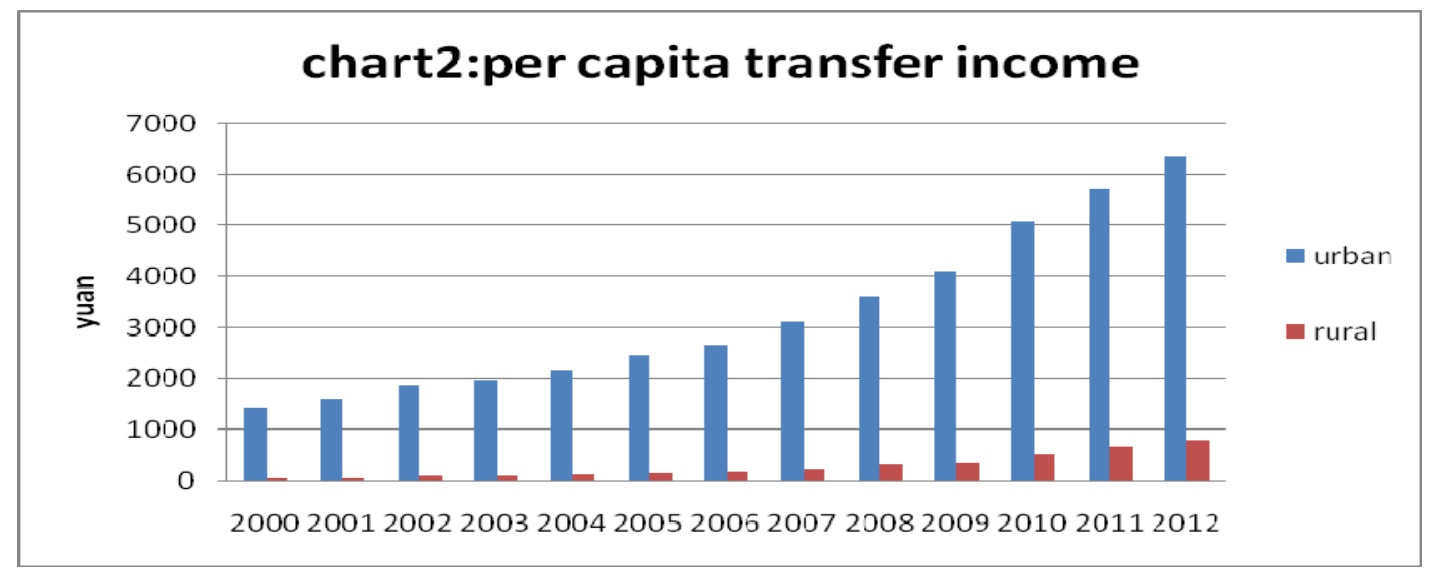

So huge gap in the social security makes the living condition in the urban is much better than in the rural, and everyone want has good ensure on medical, employment, and endowment so the migrant workers must go to the city. There are three aspects in the social security problems of migrant workers: the first question is all social security and social welfare directly link to the household registration system. Even the migrant workers who have not local household registration have made contribution for the local economic construction in a fairly long period of time; they still can not enjoy the social security and social welfare, let alone the children's education, housing and other related benefits. The second question which is the household registration must link with welfare appears again when the migrant workers want to cross different region. Some provinces have established a mechanism that the social welfare and social security network can disconnect with the household registration. In fact, the above mechanism just plays a role in several provinces. The third question is about the social security. While in rural areas have the corresponding design of social security, but the obviously differences between urban and rural areas is exist. For example, the payment of same endowment insurance between urban and rural areas has a 12.56 fold difference (Note 3). Furthermore, the situation of "citizen and farmers have same life with different price" is the reality existence in the process of compensation and subsidy. When we want to solve these problems, the government also is "absence".

It is precisely because of these problems, the citizenization for migrant workers is equivalent to enter the city or town, leaving the countryside is the best choice. But our city's current situation is: on the one hand, development of the city needs a large number of migrant workers to provide cheap labor to engage some works that local people unwilling to bear. On the other hand, in the short term, the city can not accommodate so many migrant workers and bear the corresponding social security and social obligations. This has become tangled problem as the process of the 
citizenization of migrant workers.

\section{The Response to Deal with the Absence of Government during the Citizenization of Migrant Workers} By summarizing the problems above we can find that the government in the process of the citizenization of migrant workers has exposed various "absence", and solve these problems should from two aspects of the "thought" and "action".

\subsection{The Response to Deal with the "Absence of Thought "of Government during the Citizenization of Migrant} Workers

The citizenization of migrant workers is the inevitable trend of social and economy development of China. Firstly, we must solve the question of "thought" before we analyze and solve the problems emerging in this process of the citizenization of migrant workers.

4.1.1 The Social Management More Important than the Economic Intervention Is the Rule of Macroeconomic Regulation and Control for the Government

The traditional government macro-control objectives include promoting economic growth, increasing employment, price stability and maintain the balance of international payments. The starting point for these goals is to intervene the economy by the government's "invisible hand", the "invisible hand" can solve the adverse effects of market failure and economic fluctuation. From study and reference the Marx's classic works and the socialist economic practice, western countries add to the "efficiency and fairness" in the macro-control objectives with the development of economy. This is the main reason why western countries tend to ease the social contradictions after the Second World War. Our country has its special historical background and national conditions, in a very long period of time, the development of economy is the primary goal of macro-control for China, and it has made remarkable achievements. But now, China not only has the world's political status, also has a strong economic strength, China has the ability and conditions to shift the macro-control objectives from economic growth to social development.

\subsubsection{Respect and Recognition That the Farmers Have Equal Status and Corresponding Rights Compared to Citizen}

Because the urban-rural dual structure exists in long-term, all Chinese artificially split into two classes: the citizen and the farmers, and with two kinds of different social status and treatment. At the same time, the difference of social status and treatment damage the interests of farmers. Accompany with the inertia of institution forms a kind of inertia thinking: there is a kind of unequal status between citizens and farmers, and this kind of status is correct. All of these reflect in the local governments' attitude and how to deal with migrant workers.

The government will relax the control on the migrant workers when the development of economy needs cheap labor; and the government will restrict on the flow of migrant workers through threshold when the development of economy encounters problems and needs to ensure employment for local residents. This kind of view has already penetrated into daily decision and behavior of many government departments. So we must clear a basic understanding of the problem of migrant workers from thought. Any one of the People's Republic of China has equal status, enjoy the same rights, whether he lives in urban or rural areas, whether he is a local citizen or flow from other area. Only this thought is established, it can provide an objective starting point for understanding, analysis and solve all problems about the migrant workers.

4.1.3 The Central Government Strengthens the Capacity of Coordination and Clears the Responsibility and Obligation of Government Agencies at All Levels

On the relation between the all levels of government, firstly, government must clear the responsibility and obligation at all levels, especially the responsibilities and obligations of central government and local government in the citizenization of migrant workers. Under the current fiscal decentralization system, the local government only gains the $30 \backslash \%$ of government receipts, but deals with $70 \backslash \%$ of daily work (Note 4 ). In the process of citizenization, the local government undertakes more responsibility and pressure with heavy financial burden, so it is one of the reasons why the attitude is negative when the local government faces the citizenization of migrant workers. Considering these, this kind of allocation ratio should be changed and adjusted according to the actual situation. The responsibility and obligation should be borne by the local government must be resolutely finished, the local government can't make a bargain with the central government. The responsibility and obligation should be borne by the central government must take the lead in realizing without vague and delay. Secondly, the central government should strengthen the capacity of coordination. The flow of labor is often across the different regions, individual province cannot solve properly on this issue. In order to resolve the flow of labor's problem, the central government must make the comprehensive coordination. Relate to national problems such as social security and household registration, only the central government has the ability to coordinate and solve that by cross the different regions and departments. 


\subsection{The Response to Deal with the "Absence of Action" of Government during the Citizenization of Migrant Workers}

In order to take concrete action to solve the problems in the process of the migrant workers' citizenization, the government can take steps from three main aspects that are political rights, economic rights and social security.

\subsubsection{Government Should Take Steps to Put the Political Rights of Migrant Workers into Practice}

The way of migrant workers' participation in the political participation that can draw lessons from the method of some provinces to participate in the social security. If the migrant workers can continuous work for a certain number of years in same area, they will automatically get the power to participate in local politics. If that becomes reality, it will provide the system guarantee for the migrant workers to safeguard their own political rights according the law. At the same time, for safeguard the specific political rights, the state should be specific the duties of different department, especially clear the duties of neighborhood committees, community, trade unions, women's federations, all-china youth federation. The government should make clear regulations, so the migrant workers know exactly where the exercise of political power and how to legitimate rights. Due to the arrangement and design of the system relates to political rights is the basic duty of the National People's Congress, so this kind of coordinate and organize work only can be done by the central government.

\subsubsection{Government Should Take Steps to Put the Economic Rights of Migrant Workers into Practice}

There are many questions involve into the economic rights of migrant workers, but the key problem of those is the ownership and allocation problem involves into the land rights and interests, and this is one which must be resolved by the government. To solve this problem, also requires the central government to organize and coordinate. First of all, the government must clear that the rights of land ownership and the citizenization of migrant workers are two separate issues, farmers give up the rights of land ownership is not the condition of the citizenization. Connect the two is the wrong behavior and must be prohibited. Secondly, the farmer's contracted land and homestead should be treated differently. For the question of land ownership, due to the basic system of socialism on the definition and distribution of interests of all the people, only can be solved by the relative legislation institutions and research institutions of the National People's Congress. So this question can temporarily be shelved. But the discount and pay cash problem of unexpired contract land's reasonable long-term benefits must be clear, which involves into the investment that farmer have paid. For the question of which involves into farmer owned real estate's economic interests, we can draw lessons from the successful experience in many parts of other countries. Based on the voluntary, allow the homestead and relative economic interests flow freely and orderly in the market. Of course, the state must formulate the relevant regulations and laws about the use of land, the land's corresponding valuation, the parties involved into the transaction, land swaps and so on.

\subsubsection{Government Should Take Steps to Put the Social Security of Migrant Workers into Practice}

The government wants to solve the question of social security in the process of citizenization of migrant workers should start from three aspects: first, the content and form of the social security and social welfare should be clearly defined, and the social security and social welfare should separate from the household registration system completely. The government must determine a fundamental criterion: Enjoy the social security and social welfare is the legitimate demands for every worker. Any a laborer can enjoy the social security and social welfare after lasting work for certain years, weather he is or not the local household register does not need to consider. This is not only the reasonable relationship between laborers and social security, and makes the household registration system really return to the original meaning of population management. Second, the central government should try the best to play the ability of coordination. Especially, the central government should build a mechanism of share benefits and costs between the labor outflow and inflow provinces. This requires to establishing a truly nationwide social security system, the social security of migrant workers can not only flow with the people, but also implement at working place. Third, the government should increase investment and system innovation of rural social security system. The better social security and social welfare is an important reason that causes the migrant workers want to enter the urban. If the government can establish a social security system as good as the urban in rural areas, this will make the citizenization of migrant workers achieve at local. This requires the government increases the investment in rural social security system. On the other hand, the government will step up institutional innovation and allows the funds come from different channels enter into the rural social security system. This will create a more perfect rural social security system with the help of all sectors of society.

The first industry's decline of proportion in the national economy and the employment number in the total workforce is the inevitable trend of history has been proved by economic development. After that, there are a large number of agricultural labor enter to the non-agricultural industries, as well as the working's industrialization and welfare's citizenization. A large number of labor present to towns or cities in economic development is the inexorable trend of China. Because of various problems in China's urban development and construction at the present stage, It's an impossible mission and goal that the urban or city can accept all the agricultural population transfer from rural areas 
in short-terms. So, research and implement the question of how to speed up the citizenization of migrant workers is better than debate on other issues. Through the above analysis we can find: the citizenization of migrant workers is a macro issues on national level. Many China's problems present in the process of citizenization of migrant workers are caused be the government's "absence". If the government can change the way of thought, reduce the intervention in the economic development, pay more attention to social management at the same time, then the "absence of government" will become to the "in place of government". This is not only for the citizenization of migrant workers, but also for guarantees the every one of civics' political rights, economic rights and social security in China has positive and important significance.

\section{References}

Guan, Xiqiang. (2011). In the citizenization of farmers from the perspective of the economics on human development. Reformation and Strategy, (6), 3-7.

Guo, Xi, \& Li, Haixing. (2012). The role of government in the urban and rural area's development. Inner Mongolia Social Sciences, (3), 18-21.

$\mathrm{Hu}$, Jiecheng. (2012). The migrant workers' obstacles and countermeasures in the citizenization. Macroeconomic Management, (3), 33-35.

Huang, Kun. (2011). The theory analysis of the dualistic economy's Influence for the citizenization of migrant workers. Statistics and Decision, (22), 82-85.

Huang, Yingjun, \& Zheng, Jun. The reflection and reconstruction of China's urban and rural area's social security system. Insurance Studies, (4), 52-60.

Lei, Bingyin, \& Zhou, Renjie. (2012). On the objectives of socialist macro control. China Business and Market, (6), 56-61.

Li, Yuzhu. (2012). Reflection and innovation on the China's urbanization. Chinese Journal of Population Science, (3), 106-110.

Liu, Aiyu. (2012). Urbanization and migrant's citizenlization process. Chinese Public Administration, (1), 112-117.

Liu, Yuxia, \& Liu, Junfeng. (2011). Analysis the farmers' questions in the citizenization. Inquiry into Economic Issues, (5), 30-33.

Sheng, Guangyao. (2011). A literature review on the research of urbanization's pattern. Urban Studies, (7), 13-19.

Song, Rendeng. (2012). Citizenization of farmers in the process of urbanization. Journal of Shandong University, (1), 27-31.

Tang, Yunlong. (2011). Turning migrant workers into city residents: actual dilemma and realization of rights and interests. Journal of Shanghai University of Finance and Economics, 13(5), 34-41.

Wu, Yemiao. (2012). The difficulties and countermeasures of suburban peasants in the citizenization. China Rural Survey, (3), 71-78.

Xiao, Jingcheng. (2012). Analysis of the basic way of the citizenization of migrant workers and Chinese urbanization. China Economic and Trade Herald, (7), 27-29.

Yu, Jia, \& Ding, Jinghong. (2010). The reform orientation and step selection of China's household registration system. Journal of East China Normal University, (4), 65-71.

$\mathrm{Yu}$, Zhiyong. (2012). Focus on the rural urbanization and the orientation of the government functions. Rural Economy, (3), 102-105.

Zhang, Liyan, \& Li, Juan. (2012). Research on the incentive of bilateral system of migrant workers enter into the city. Social Science Journal, (3), 164-166.

\section{Notes}

Note 1. Research Group of Development Research Centre of the State Council. 2011. The General Situation and Strategy Orientation of the Citizenization Process of the Migrant Workers. Reform (05), 5-29.

Note 2. Yun-long, TANG, 2011. Turning migrant workers into city residents: actual dilemma and realization of rights and interests. Journal of Shanghai University of Finance and Economics, 13(5), 34-41.

Note 3. Ying-jun, HUANG. Jun, ZHENG. The reflection and reconstruction of China's urban and rural social security system. Insurance Studies, (04), 52-60.

Note 4. Zhi-yong, YU. Focusing on the rural urbanization and the orientation of the government functions. Rural Economy, (03), 102-105. 